\title{
Comparison of detection of human papillomavirus 16 DNA in cervical carcinoma tissues by Southern blot hybridisation and nested polymerase chain reaction
}

\author{
D. Y. CHANG, C. Y. HSIEH, R. J. CHEN, S. C. LEE* and S.-C. HUANG $\dagger$
}

Department of Obstetrics and Gynecology and "Institute of Molecular Medicine, College of Medicine and Hospital, National Taiwan University, Taipei, Taiwan

\begin{abstract}
Summary. An association between human papillomavirus (HPV) and cervical neoplasia has been widely reported and HPV DNA is commonly detected in cervical carcinoma tissues. However, estimates of the prevalence of HPV infection differs among various detection methods. Seventy cases of cervical carcinoma were screened for HPV 16 infection by Southern blot hybridisation (SBH) and nested polymerase chain reaction (PCR). According to SBH, the prevalences of HPV 16 DNA in stage I $(n=40)$ and stage II $(n=30)$ cervical carcinomas were 52.5 and $63.3 \%$, respectively, and the overall prevalence was $57.1 \%$ (40 of 70). By nested PCR, the prevalences of HPV 16 infection in stage I and II cervical carcinomas were 87.5 and $93.3 \%$, respectively, and the overall prevalence was $90.3 \%$. The prevalence of HPV DNA detected by nested PCR was significantly greater than that detected by SBH. The combined concordance of positive and negative results between SBH and nested PCR was $61.4 \%$. The discrepancy resulted mainly from 25 cases $(35.7 \%)$ that were positive by PCR but negative by SBH. A small copy number of HPV DNA in these 25 cases was documented by a semi-quantitative PCR method. The nested PCR was more sensitive than SBH and detected cases with low amounts of HPV DNA. The detection of HPV infection varied between these two prevailing detection methods and this should be kept in mind in assessing various epidemiological data concerning HPV infection.
\end{abstract}

\section{Introduction}

The association of human papillomavirus (HPV) infection and cervical neoplasia has been widely reported. ${ }^{1,2}$ More than 60 genotypes of HPV have been identified and $>22$ genotypes are related to genital infection. ${ }^{3,4}$ Among them, HPV types 6 and 11 are more commonly seen in benign gynaecological lesions such as condylomata accuminata, ${ }^{5}$ whereas HPV types 16 and 18 are more commonly seen in malignancies of the lower genital tract, especially cervical carcinomas. ${ }^{6.7}$ The prevalences of HPV 16 and 18 DNA in cervical carcinoma tissues greatly exceed those in normal cervical tissues. ${ }^{8}$

The prevalence of HPV infection varies between reports. The recorded prevalence rates of HPV 16 or 18 DNA in cervical carcinoma tissues by hybridisation methods in the UK. Germany, the USA and Japan range from 18 to $92 \% .^{9}$ The great variation in

Received 23 Feb. 1995; revised version accepted 2 May 1995. †Correspondence should be sent to Professor S.-C. Huang. prevalence may result from geographic or racial differences. ${ }^{6,10}$ However, other factors such as test design and detection methods may also be responsible for the discrepancy. Although Southern blot hybridisation ( $\mathrm{SBH}$ ) is generally accepted as the ultimate standard method, it is expensive and laborious and a large amount of sample is required for analysis. ${ }^{11} \mathrm{On}$ the other hand, polymerase chain reaction (PCR) is much more sensitive than Southern or other conventional DNA hybridisation methods ${ }^{12}$ and a small sample is adequate for PCR analysis. ${ }^{13,14}$ Moreover, the sensitivity and specificity can be increased by means of a two-step PCR with nested primers. ${ }^{15}$ Nested PCR has been applied to detect hepatitis C virus (HCV), human immunodeficiency virus (HIV), herpes simplex virus (HSV) and HPV. ${ }^{16-19}$ Exploring the variation in prevalence detected by SBH and PCR is important in assessing epidemiological data of HPV infection. In the present work, HPV 16 DNA, the most prevalent virus in cervical carcinoma tissues, was screened by both SBH and PCR methods and the underlying cause of the discrepant screening results 
between these two methods was sought by application of a semi-quantitative PCR analysis.

\section{Materials and methods}

\section{Subjects and specimens}

Seventy cases of histologically proven cervical carcinoma were studied. The clinical staging of cervical cancer followed the system of the International Federation of Gynecology and Obstetrics (FIGO). There were 40 stage I $(57 \cdot 1 \%)$ and 30 stage II (42.9\%) cases. The mean ages of cases with stage I and stage II disease were 46.6 and $51 \cdot 2$ years, respectively. The difference in ages between these two groups of patients was not significant $(t=1.71, p=0.092)$. The carcinoma tissues were collected from the surgical specimens immediately after radical hysterectomy and stored in liquid nitrogen until use. The genomic DNA of carcinoma tissues was extracted by a phenol-chloroform-ethanol method and the concentrations of genomic DNA were determined by spectrophotometry. ${ }^{20}$

\section{Southern blot hybridisation}

Southern blot hybridisation was done as described previously. ${ }^{8}$ Briefly, genomic DNA $(10 \mu \mathrm{g})$ was digested with restriction endonucleases such as BamHI, HindIII and PstI, then subjected to agarose gel electrophoresis and subsequently blotted on to nitrocellulose membranes. The HPV probes were prepared by labelling the entire genomic HPV 16 DNA, which had been separated and purified from its vector pBR-322, with $\left[\alpha^{32} \mathrm{P}\right]-\mathrm{dCTP}$. Prehybridisation, hybridisation and washing were performed under highly stringent conditions. Hybridisation was detected by autoradiography. The sensitivity of SBH was c. $1 \mathrm{pg}$ of standard HPV DNA.

\section{$P C R$}

Cellular genomic DNA (500 ng, each case) and purified HPV DNA (100 pg, positive control) were used as target DNA. Each sample was amplified in a reaction mixture $(100 \mu \mathrm{l})$ containing: PCR buffer$50 \mu \mathrm{M} \mathrm{KCl}, 10 \mathrm{~mm}$ Tris-HCl, pH 8.3, $1.5 \mathrm{mM} \mathrm{MgCl}_{2}$ and gelatin $0.01 \%$; primers mix, each $0.2 \mu \mathrm{M}$, (outer primer pairs in the first-step PCR and inner primer pairs in the second-step PCR); dNTP (deoxynucleoside triphosphąte, mix: dATP, dTTP, dCTP, dGTP; Sigma, each $50 \mu \mathrm{M}$ ); and Taq DNA polymerase (Cetus, USA), 2 units. Salmon sperm DNA (500 ng) was used as the negative control and reaction mixture without target genomic DNA was used as the blank. Amplification was performed with an automated thermal cycler (Perkin-Elmer Cetus, USA) with denaturing conditions of $95^{\circ} \mathrm{C}$ for $2 \mathrm{~min}$, followed by repeated cycles of $94^{\circ} \mathrm{C}, 55^{\circ} \mathrm{C}$ and $72^{\circ} \mathrm{C}$ for $1 \mathrm{~min}$ each (35 cycles in total), and a final extension at $72^{\circ} \mathrm{C}$ for 10 min. After the first-step PCR, a portion $(10 \mu \mathrm{l})$ of the reaction mixture was used as the source of target DNA in the second-step PCR for further amplification. The PCR reaction was prepared in a hood restricted to this purpose. There was overnight treatment of laminar flow and ultraviolet irradiation in the hood between each run of the PCR. The sequences of nested outer and inner primers used in the two steps of the PCR are shown in table I.

After each run of the PCR, the reaction mixtures were tested for positive signals by gel electrophoresis and dot-blot hybridisation. For gel electrophoresis, $15 \mu \mathrm{l}$ of reaction mixture was separated by electrophoresis on an agarose $1.6 \%$ gel stained with ethidium bromide. Positive bands of corresponding size were recorded (fig. 1). For verification by dot-blot hybridisation, $15 \mu \mathrm{l}$ of reaction mixtures were dot-blotted on to a nylon membrane. Prehybridisation was followed by hybridisation with non-isotopic, digoxigeninlabelled HPV oligonucleotide probes $(10 \mathrm{ng} / \mathrm{ml})$ derived also from PCR incorporating digoxigenindUTP. ${ }^{21,22}$ After stringent washing and development with a digoxigenin-anti-digoxigenin-alkaline phosphatase system, according to the manufacturer's instructions (Boerhinger Mannheim, Germany), positive signals were recorded for comparison. Only those samples that gave positive bands in electrophoresis and dot signals were interpreted as positive for HPV infection. The sensitivity of nested PCR was tested with serial dilutions of standard HPV DNA. As little as $10^{-6} \mathrm{pg}$ of standard HPV DNA was detectable by this method.

\section{Semi-quantitative PCR}

To prepare a competitive DNA fragment for semiquantitative PCR, the originally amplified native HPV 16 DNA fragment (694 bp; nucleotides 7836-625) was

Table I. Sequences of HPV 16 primers used in nested PCR

\begin{tabular}{llcc}
\hline \multicolumn{1}{c}{$5^{\prime} \rightarrow 3^{\prime}$ sequence } & Genomic site & Size (bp) \\
\hline First-step outer primers & & \\
16 1R & ACTGCACATG GGTGTGTGCA AACC & $7836-7859$ & 694 \\
1L $\quad$ GATCAGTTGT CTCTGGTTGC AAAT & $625-602$ & \\
Second-step inner primers & & \\
16 2R & ACCGAAACCG GTTAGTATAA AAGC & $50-73$ & 552 \\
2L & CTAACATATA TTCATGCAAT GTAG & $601-578$ & \\
\hline
\end{tabular}




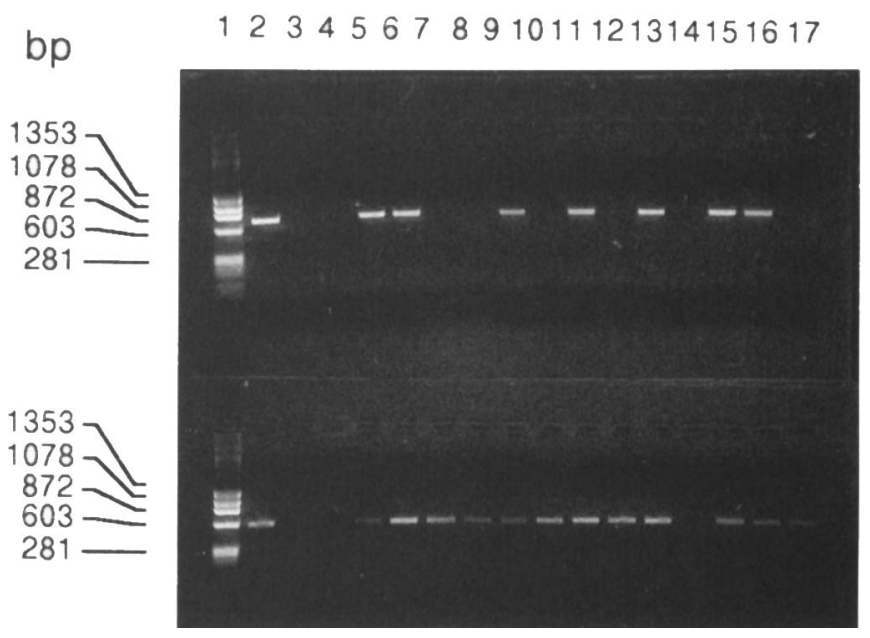

Fig. 1. Agarose gel electrophoresis of amplified HPV 16 DNA fragments from genomic DNA of cervical carcinoma tissues following nested PCR. Upper row (first-step PCR): lane 1, size marker, Phi-X174/HaellI (1 $\mu \mathrm{g}) ; 2-4$, positive (694 bp) and negative controls and blank, respectively; 5 17, samples. Lower row (second-step PCR): lane 1, size marker, Phi-X174/HaeIII (1 $\mu$ g); 2-4, positive (552 bp) and negative controls and blank, respectively; 5-17, samples.

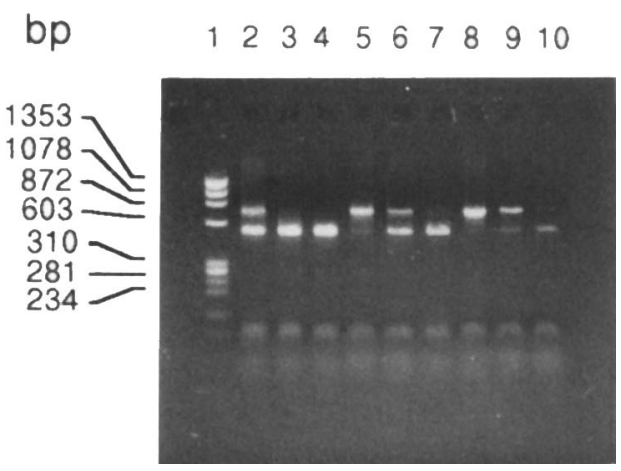

Fig. 2. Relative intensity of amplified HPV DNA bands on electrophoresis following semi-quantitative PCR. Lane 1, size marker, Phi-X174/HaeIII; 2-4, 0.1,0.01 and $0.001 \mathrm{pg}$, respectively, of native HPV DNA in addition to $0.1 \mathrm{pg}$ of modified HPV 16 DNA in the reaction mixtures; 5-7,0.1,0.01 and $0.001 \mathrm{pg}$, respectively, of native HPV DNA in addition to $0.01 \mathrm{pg}$ of modified HPV 16 DNA; 8-10, $0.1,0.01$ and $0.001 \mathrm{pg}$, respectively, of native HPV DNA in addition to $0.001 \mathrm{pg}$ of modified HPV 16 DNA. The iso-dense bands of the amplified native $(694 \mathrm{bp})$ and the modified competitive (494 bp) HPV DNA appeared when the relative amounts of these two DNA templates in the samples were similar, e.g., lanes 2 and 6 .

cut with HinfI at the sites (GANTC) of nucleotides 274 and 474 into three fragments - 343 (7836-274 ntd), $200(274474)$ and $151(274675) b_{\text {bp. }}{ }^{23}$ The flanking sequences of the 343- and 151-bp fragments were purified by electrophoresis and electro-elution, then ligated with a DNA ligase to form a novel DNA of 494 bp. This 494-bp DNA fragment was used as a competitive target DNA for amplification because it possessed the same flanking sequences as that of native DNA (694 bp). The novel competitive short (494-bp) DNA fragment could be amplified by PCR and quantified for further use. Moreover, the amplified native 694-bp and competitive 494-bp DNA fragments were clearly distinguished by their different sizes on gel electrophoresis. In the semi-quantitative PCR, the competitive DNA at a known concentration was added to the reaction mixture. The predominance of DNA bands (competitive or native DNA) on electro- phoresis after PCR depended on the relative amounts of these two target DNAs in the samples before amplification. The appearance of two iso-dense bands or the transition from one dominant band to another, either native or competitive DNA fragments, on electrophoresis indicated that the amount of the native DNA in this sample was identical to or near the known amount of competitive DNA fragment multiplied by a factor 16 (7904 bp/494 bp). In this design of semiquantitative PCR, the concentrations of HPV DNA in samples could be estimated at less than pg levels (fig. 2).

\section{Results}

\section{Prevalence by Southern blot hybridisation and nested PCR}

The prevalences of HPV 16 DNA in cervical carcinoma tissues by $\mathrm{SBH}$ in stage I and stage II patients were $63.3 \%$ (19 of 30 ) and $52.5 \%$ (21 of 40 ), respectively. The overall prevalence rate was $57 \cdot 1 \%$ (40 of 70) (table II). Conversely, the prevalences of HPV 16 DNA in cervical carcinoma tissues by nested PCR in stage I and stage II patients were 87.5 (35 of 40) and $93.3 \%$ (28 of 30 ), respectively. The overall prevalence rate was $90.0 \%$ (63 of 70$)$. The difference in

Table II. Stage-specific prevalence of HPV 16 DNA in cervical carcinoma tissues by $\mathrm{SBH}$ and nested PCR

\begin{tabular}{|c|c|c|c|c|}
\hline \multirow[b]{2}{*}{ Method } & \multirow[b]{2}{*}{ Status } & \multicolumn{3}{|c|}{ Number $(\%)$ of samples } \\
\hline & & $\begin{array}{l}\text { Stage I } \\
(n=40)\end{array}$ & $\begin{array}{l}\text { Stage II } \\
(\mathrm{n}=30)\end{array}$ & $\begin{array}{c}\text { Total } \\
(n=70)\end{array}$ \\
\hline SBH & $+v e$ & $21(52 \cdot 5)$ & $19(63 \cdot 3)$ & $40(57 \cdot 1)$ \\
\hline SBH & $-\mathrm{ve}$ & $19(47 \cdot 5)$ & $11(36 \cdot 7)$ & $30(42.9)$ \\
\hline PCR & $+v e$ & $35(87 \cdot 5)$ & $28(93 \cdot 3)$ & $63(90 \cdot 0)$ \\
\hline PCR & $-v e$ & $5(12 \cdot 5)$ & $2(6 \cdot 7)$ & $7(10 \cdot 0)$ \\
\hline
\end{tabular}


Table III. Comparison of the prevalence of HPV 16 DNA in cervical carcinoma tissues detected by SBH and nested PCR

\begin{tabular}{lcccc}
\hline & & \multicolumn{3}{c}{ Number (\%) of samples } \\
\cline { 3 - 5 } Method & Status & SBH +ve & SBH -ve & Concordance \\
\cline { 3 - 5 } & & & & \\
Stage I (n = 40) & & & & \\
Nested PCR & + ve & $19(47 \cdot 5)$ & $16(40 \cdot 0)$ & \\
Nested PCR & - ve & $2(0 \cdot 5)$ & $3(7 \cdot 5)$ & $55 \%(22 / 40)$ \\
Stage II (n = 30) & & & & \\
Nested PCR & + ve & $19(63 \cdot 3)$ & $9(30 \cdot 0)$ & \\
Nested PCR & - ve & $0(0 \cdot 0)$ & $2(6 \cdot 6)$ & $70 \%(21 / 30)$ \\
Stage I \& II (n $=70)$ & & & \\
Nested PCR & + ve & $38(54 \cdot 3)$ & $25(35 \cdot 7)$ & \\
Nested PCR & - ve & $2(2 \cdot 9)$ & $5(7 \cdot 1)$ & $61 \%(43 / 70)$ \\
\hline
\end{tabular}

prevalence between stage I and stage II patients was not significant either by SBH $\left(\chi^{2}=0.439, p=0.508\right)$ or by nested PCR $\left(\chi^{2}=0 \cdot 162, \mathrm{p}=0 \cdot 687\right)$. However, the overall prevalence rate by nested PCR $(90.0 \%)$ was much greater than that by SBH $(57 \cdot 1 \%)\left(\chi^{2}=17 \cdot 78\right.$, $\mathrm{p}<0.001)$.

\section{Comparison of prevalences detected by Southern blot hybridisation and nested PCR}

Comparisons between SBH and nested PCR for detecting HPV 16 DNA in cervical carcinoma tissues are shown in table III. In total, $38(54.3 \%)$ patients had concordant positive and five $(7 \cdot 1 \%)$ cases had concordant negative results by SBH and PCR methods. The combined concordance of positive and negative results between these two methods was $61.4 \%$ (43 of 70). The discrepancy resulted mainly from 25 $(35.7 \%)$ cases, whose samples were positive by nested PCR but negative by SBH. The amounts of HPV 16 DNA determined by the semi-quantitative PCR in the samples from these 25 cases were in the range $10^{-2}-10^{-5} \mathrm{pg}$. On the other hand, samples from two (2.9\%) further cases were positive for HPV 16 DNA by SBH but negative by nested PCR. The concordance of SBH and PCR results in those with stage II cervical carcinomas $(70 \%)$ was greater than in those with stage I disease $(55 \%)$ but the difference was not significant $\left(\chi^{2}=1 \cdot 506, p=0.304\right)$.

\section{Discussion}

HPV 16 is the predominant HPV type found in cervical carcinomas. ${ }^{24,25}$ The prevalence of HPV 16 DNA in cervical carcinoma tissues by SBH in the present work was $57.1 \%$, similar to the $53 \%$ reported by Choo et al. in Chinese women from the same geographic area of northern Taiwan. ${ }^{26}$ Both prevalence rates were in the range $35-90 \%$ found in patients studied by SBH but in different geographic regions such as Japan (35\%), East Anglia (UK) (46\%), Norway $(56 \%)$, UK $(66 \%)$, Australia $(71 \%)$ and India $(90 \%){ }^{24,25,27-30}$
As previously reported, the prevalence of HPV infection was not related to the clinical stage of the cervical cancers. ${ }^{28,31}$ The difference in prevalence between stage I and stage II patients, either by SBH or PCR, was not significant in this study. However, the prevalence of HPV infection detected by nested PCR was much greater than that by SBH.

PCR is generally many times more sensitive than Southern blot or other hybridisation methods. Melchers and colleagues reported that the prevalence of HPV DNA in cervical scrapes detected by PCR $(70 \%)$ was much larger than that by SBH or modified filter in situ hybridisation (FISH) (46\%). ${ }^{12}$ Moreover, the prevalence of HPV infection according to PCR in those with abnormal Pap smear $(67 \%)$ exceeded that by the ViraPap method in Burmer's series $(47 \%){ }^{32}$ a similar result was reported by Bauer et al.$^{33}$ In contrast, Nuovo and colleagues reported a lower detection rate of HPV in cervical lesions that lack koilocyte atypia with PCR than with SBH. ${ }^{34}$ The lower detection rate of HPV with PCR might have been related to the relatively high proportion of "novel" HPV types in such lesions. In the present work, the prevalence of HPV 16 DNA in cervical carcinoma tissues detected by nested PCR was $90 \%$, much larger than that by SBH $(57.1 \%)$ and also larger than the prevalence by one-step PCR method in cervical carcinoma specimens from women in central China $(72 \%){ }^{35}$ Generally, the sensitivity of two-step PCR is greater than that of onestep PCR and the specificity is also increased by applying nested primers. ${ }^{15,19}$ Moreover, hybridisation of the PCR product with radioactively or nonradioactively labelled oligonucleotide probes increased the sensitivity of HPV detection by $100-$ fold. ${ }^{36}$

The combined concordance of positive and negative results of HPV DNA between dot-blot hybridisation and PCR was $69 \%$ in Morris's series, ${ }^{37}$ whereas the concordance between SBH and PCR was $>80 \%$ in Guerrero's series. ${ }^{38}$ In this work, the concordance between SBH and nested PCR was $61.4 \%$. Most discrepancies resulted from the $25(35.7 \%)$ cases that gave positive PCR but negative SBH results. Similar results $(27.5 \%$ of cancer biopsies were positive by PCR but negative by SBH) have been reported by Kristiansen and colleagues. ${ }^{39}$ These findings might be explained by the relatively small copy number of HPV DNA in carcinoma tissues from these cases. In semiquantitative PCR analysis, the amounts of HPV 16 DNA in the samples of these 25 cases with discrepant PCR and SBH results were in the range $10^{-2}-10^{-5} \mathrm{pg}$, which was less than the detection limit (1 pg) of SBH. On the other hand, results in two cases $(2.9 \%)$ were positive for HPV DNA by SBH but negative by nested PCR. This discrepancy might result from non-specific binding by SBH to other HPV DNA or the presence of novel HPV types incapable of amplification by PCR with type-specific primers. ${ }^{34}$

In conclusion, the variation in prevalence of HPV DNA in cervical carcinoma tissues detected by SBH 
and nested PCR was evident and the discrepancy resulted mainly from cases having positive PCR but negative SBH results. Based on semi-quantitative PCR analysis, we believe that more cases with relatively small copy numbers of HPV DNA could be detected by nested PCR than by SBH. The influence of different screening methods on the prevalence rate of HPV infection is important; this factor should be kept in mind in assessing epidemiological data concerning HPV infection.

We thank Dr H. zur Hausen for providing HPV-positive plasmids and the National Science Council of Taiwan for financial support.

\section{References}

1. zur Hausen H. Papillomaviruses in anogenital cancer as a model to understand the role of viruses in human cancers. Cancer Res $1989 ; 49: 4677-4681$.

2. Howley PM. Role of the human papillomaviruses in human cancer. Cancer Res 1991; 51 Suppl: 5019s-5022s.

3. de Villiers E-M. Heterogeneity of the human papillomavirus group. J Virol 1989; 63: 4898-4903.

4. Nuovo GJ, Darfler MM, Impraim CC, Bromley SE. Occurrence of multiple types of human papillomavirus in genital tract lesions. Analysis by in situ hybridization and the polymerase chain reaction. Am J Pathol 1991; 138: 53-58.

5. Gissmann L, deVilliers EM, zur Hausen $\mathbf{H}$. Analysis of human genital warts (condylomata acuminata) and other genital tumors for human papillomavirus type 6 DNA. Int $J$ Cancer 1982; 29: 143-146.

6. Dürst $M$, Gissmann L, Ikenberg $H$, zur Hausen $H$. A papillomavirus DNA from a cervical carcinoma and its prevalence in cancer biopsy samples from different geographic regions. Proc Natl Acad Sci USA 1983; 80: 3812-3815.

7. Boshart M, Gissmann L, Ikenberg H, Kleinheinz A, Scheurlen W, zur Hausen $H$. A new type of papillomavirus DNA, its presence in genital cancer biopsies and in cell lines derived from cervical cancer. EMBO J 1984; 3: 1151-1157.

8. Hsieh CY, Lee SC. Huang SC. Presence and expression of human papillomavirus types 16 and 18 DNA sequences in cervical carcinomas. Asia Oceania J Obstet Gynaecol 1988 ; 14: 87-95.

9. Munoz N, Bosch X, Kaldor JM. Does human papillomavirus cause cervical cancer? The state of the epidemiological evidence. Br J Cancer 1988; 57: 1-5.

10. Herrero R. Brinton LA, Hartge $P$ et al. Determinants of the geographic variation of invasive cervical cancer in Costa Rica. Bull Pan Am Health Organ 1993; 27: 15-25.

11. Stanley M. Genital papillomaviruses, polymerase chain reaction and cervical cancer. Genitourin Med 1990; 66: 415-417.

12. Melchers W. van den Brule A, Walboomers J et al. Increased detection rate of human papillomavirus in cervical scrapes by the polymerase chain reaction as compared to modified FISH and southern-blot analysis. J Med Virol 1989; 27 : 329-335.

13. Claas ECJ. Melchers WJG, van der Linden HC, Lindeman J, Quint WGV. Human papillomavirus detection in paraffinembedded cervical carcinomas and metastases of the carcinomas by the polymerase chain reaction. Am J Pathol 1989: 135: 703-709.

14. Shibata DK. Arnheim N, Martin WJ. Detection of human papilloma virus in paraffin-embedded tissue using the polymerase chain reaction. $J$ Exp Med 1988; 167: 225-230.

15. Evander M. Edlund K, Bodén E et al. Comparison of a one-step and a two-step polymerase chain reaction with degenerate general primers in a population-based study of human papillomavirus infection in young Swedish women. $J$ Clin Microbiol 1992; 30: 987-992.

16. Garson JA, Tedder RS, Briggs M et al. Detection of hepatitis C viral sequences in blood donations by "nested " polymerase chain reaction and prediction of infectivity. Lancet 1990; 335: $1419-1422$.

17. Aurelius E, Johansson B, Sköldenberg B, Staland A, Forsgren M. Rapid diagnosis of herpes simplex encephalitis by nested polymerase chain reaction assay of cerebrospinal fluid. Lancet 1991; 337: 189-192.

18. Albert J. Fenyö EM. Simple, sensitive, and specific detection of human immunodeficiency virus type 1 in clinical specimens by polymerase chain reaction with nested primers. $J$ Clin Microbiol 1990; 28: 1560-1564

19. Williamson AL, Rybicki EP. Detection of genital human

papillomaviruses by polymerase chain reaction amplification with degenerate nested primers. J Med Virol 1991; 33: $165-171$.

20. Sambrook J, Fritsch EF, Maniatis T. Molecular cloning: a laboratory manual, 2nd edn. Cold Spring Harbor, Cold Spring Harbor Press. 1989: E.3-E.10.

21. Syrjanen S, Andersson B, Juntunen L, Syrjanen K. The use of polymerase chain reaction in generation of biotinylated human papillomavirus DNA probes for in situ hybridization. J Virol Methods 1991; 31 : 147-159.

22. Day PJR, Bevan IS, Gurney SJ, Young LS, Walker MR. Synthesis in vitro and application of biotinylated DNA probes for human papilloma virus type 16 by utilizing the polymerase chain reaction. Biochem $J 1990 ; 267$ : 119-123.

23. Baker CC. Sequence analysis of papillomavirus genomes. In: Salzman NP, Howley PM (eds) The Papovaviridae, vol. 2; The papillomaviruses. New York, Plenum. 1987: 321--385.

24. Yaegashi N, Yajima H, Shikano K et al. Detection of human papillomavirus (HPV) type 16 and 52b in cervical cancer tissues by Southern blot hybridization and polymerase chain reaction (PCR). Virus Genes 1990; 4: 313-323.

25. Das BC, Sharma JK, Gopalkrishna V et al. A high frequency of human papillomavirus DNA sequences in cervical carcinomas of Indian women as revealed by Southern blot hybridization and polymerase chain reaction. $J$ Med Virol 1992; 36: 239-245.

26. Choo KB, Pan CC, Liu MS et al. Presence of episomal and integrated human papillomavirus DNA sequences in cervical carcinoma. J Med Virol 1987; 21 : 101-107.

27. Scholl SM, Pillers EM, Robinson RE, Farrell PJ. Prevalence of human papillomavirus type 16 DNA in cervical carcinoma samples in East Anglia. Int J Cancer 1985; 35: 215-218.

28. Sebbelov AM, Kjorstad KE, Abeler VM, Norrild B. The prevalence of human papillomavirus type 16 and 18 DNA in cervical cancer in different age groups: a study on the incidental cases of cervical cancer in Norway in 1983. Gynecol Oncol 1991; 41 : 141-148.

29. Meanwell CA, Cox MF, Blackledge G, Maitland NJ. HPV 16 DNA in normal and malignant cervical epithelium: implications for the aetiology and behaviour of cervical neoplasia. Lancet 1987; 1: 703-707.

30. Kulski JK, Howard MJ, Pixley EC. DNA sequences of human papillomavirus types 11,16 or 18 in invasive cervical carcinoma of Western Australian women. Immunol Cell Biol 1987; 65: 77-84.

31. Chen TM, Chen CA, Wu CC, Huang SC, Chang CF, Hsieh CY. The genotypes and prognostic significance of human papillomaviruses in cervical cancer. Int J Cancer 1994; 57 : 181-184.

32. Burmer GC, Parker JD, Bates J, East K, Kulander BG. Comparative analysis of human papillomavirus detection by polymerase chain reaction and Virapap/Viratype kits. Am J Clin Pathol 1990; 94 : 554-560.

33. Bauer HM, Ting Y, Greer CE et al. Genital human papillomavirus infection in female university students as determined by a PCR-based method. JAMA $1991 ; 265: 472-477$.

34. Nuovo GJ. Human papillomavirus DNA in genital tract lesions histologically negative for condylomata. Analysis by in situ, Southern blot hybridization and the polymerase chain reaction. Am J Surg Pathol 1990; 14: 643-651.

35. Xiao X, Cao M, Miller TR, Cao Z-Y, Yen TSB. Papillomavirus DNA in cervical carcinoma specimens from central China. Lancet 1988; 2: 902.

36. Morrison EA, Goldberg GL, Kadish AS, Burk RD. Polymerase chain reaction detection of human papillomavirus: quantitation may improve clinical utility. J Clin Microbiol 1992; 30: $2539-2543$.

37. Morris BJ, Rose BR, Flanagan JL et al. Automated polymerase 
chain reaction for papillomavirus screening of cervicovaginal lavages: comparison with dot-blot hybridization in a sexually transmitted diseases clinic population. $J$ Med Virol 1990; 32: 22-30.

38. Guerrero E, Daniel RW, Bosch FX et al. Comparison of ViraPap, Southern hybridization, and polymerase chain reaction methods for human papillomavirus identification in an epidemiological investigation of cervical cancer. $J$ Clin Microbiol 1992; 30: 2951-2959.

39. Kristiansen E, Jenkins A, Kristensen $\mathrm{G}$ et al. Human papillomavirus infection in Norwegian women with cervical cancer. APMIS 1994; 102: 122-128. 